\title{
Intensivist nurse performance in the collaborative model of continuous hemodialysis: links with patient safety
}

\author{
Atuação do enfermeiro intensivista no modelo colaborativo de \\ hemodiálise contínua: nexos com a segurança do paciente \\ Actuación del enfermero intensivista en el modelo colaborativo de \\ hemodiálisis continua: nexos con la seguridad del paciente
}

How to cite this article:

Andrade BRP, Barros FM, Lúcio HFA, Campos JF, Silva RC. Intensivist nurse performance in the collaborative model of continuous hemodialysis: links with patient safety. Rev Esc Enferm USP. 2019;53:e03475. DOI: http://dx.doi.org/10.1590/S1980-220X2018004603475

Bianca Ribeiro Porto de Andrade ${ }^{1}$

Fabiana de Mello Barros ${ }^{1}$

Honorina Fátima Ângela de Lúcio ${ }^{1}$

Juliana Faria Campos ${ }^{1}$

Rafael Celestino da Silva ${ }^{1}$

1 Universidade Federal do Rio de

Janeiro, Escola de Enfermagem Anna

Nery, Rio de Janeiro, RJ, Brazil.

\section{ABSTRACT}

Objective: To describe the Intensive Care Unit nurse's role in the management of continuous hemodialysis within the scope of the collaborative model, analyzing it regarding the links with patient safety. Method: A descriptive, qualitative, exploratory study based on the Reason safety model performed at the Intensive Care Unit of a specialized hospital, with nurses working in the direct management of continuous hemodialysis, who were interviewed using a script with its contents being thematically analyzed. Results: 23 nurses participated. The role of the intensive care nurse in continuous hemodialysis involves performing preparation/planning and monitoring/follow-up activities, based on interaction with technology and the application of specialized knowledge. The adopted collaborative model reflects on its qualification and availability in relation to the activities that need to be performed, with repercussions on patient safety. Conclusion: There are weaknesses in the participation by intensive care nurses in this continuous hemodialysis model which require elaboration of defensive barriers for the safety of the system.

\section{DESCRIPTORS}

Critical Care Nursing; Renal Dialysis; Biomedical Technology; Patient Safety 


\section{INTRODUCTION}

Intensive Care Units (ICUs) are intended for the care of critically ill patients who require uninterrupted health care and who require specialized equipment and resources. One of the complications that may occur in this environment is acute kidney injury (AKI), a common occurrence in patients under intensive care ${ }^{(1)}$.

AKI has been defined as an unexpected decrease in the glomerular clearance rate from different diagnostic criteria, among which the most accepted are based on decreased urine output and elevated serum creatinine ${ }^{(2)}$. In the ICU scenario, this condition has an incidence and mortality rate ranging up to $70 \%{ }^{(3-4)}$.

In view of this, renal replacement therapy is widely used in the ICU, especially continuous hemodialysis (HD). This statement is reiterated by the fact that among the most severe cases, up to $70 \%$ of patients with AKI will receive $\mathrm{HD}^{(5)}$. Continuous $\mathrm{HD}$ is used in treating AKI patients with hemodynamic instability in the ICU. This technique performs continuous blood clearance and removal of excess fluids and liquids, with fewer complications and higher patient safety ${ }^{(6-7)}$.

Although the medical team was initially responsible for conducting the dialysis process, over time nursing started to actively participate in this process. Nurses currently play a key role in continuous $\mathrm{HD}$, being responsible for the patient, machinery and monitoring, contributing to its safety and efficacy ${ }^{(8)}$.

Regarding this aspect, studies describe three models of nurses' performance when using continuous $\mathrm{HD}^{(9-}$ 10). There is the model in which the specialist nurse in nephrology is responsible for conducting the therapy, because they have the technical and specialized knowledge which enables them to better manage continuous hemodialysis. However, they have a disadvantage in the number of professionals and in conflicts with the ICU nurses ${ }^{(10)}$.

The second model is that conducted entirely by the ICU nurse, with the advantages of being able to conduct early treatment, the ease of hemodynamic evaluation of the patient and eliminating conflicts. The collaborative model has the participation of the nephrologist nurse and the ICU nurse, providing an exchange of knowledge. Thus, some ICUs have collaborated with the dialysis units so that nurses in this sector can assist during continuous hemodialysis ${ }^{(10)}$.

This role of the nurse in the management of continuous HD is under discussion around the world. For example, in Italy there is no standardized protocol for HD management in the ICU, as each unit uses its resources according to local resources ${ }^{(9)}$. In the discussion about HD logistics and the implications for the ICU nurse, it is stated that ICU dialysis is controversial, thus raising questions about cost, staff, management and quality ${ }^{(11)}$.

Such discussion considers that most of the responsibility lies with the ICU nurse, who is responsible for initiating therapy, monitoring, and troubleshooting. The maintenance, continuing education, competence and quality assurance of the therapy is also the responsibility of the ICU, while the establishment of policies and procedures are attributions of the ICU nurse along with nephrology specialists ${ }^{(11)}$.

When analyzing the role of the ICU nurse in relation to the renal clearance techniques, another author argues that what is most advantageous among the three care organization models is the model organized by the ICU nurse because of their knowledge about patient conditions, their treatment and the handling of the equipment ${ }^{(10) .}$

This debate about the advantages and disadvantages in the application of each of these models and about the professional who is better prepared to conduct such therapy evidences a lack of definition about the ICU nurse's role. Thus, despite being a procedure with high technological value, there is still variation in its application in practice ${ }^{(12)}$.

Regarding this study, the exploratory observation of applying the continuous HD collaborative model brought to light a reflection on the ICU nurse's role in this model and the implicated risks to patient safety, especially regarding adverse events from managing this technology. This reflection is based on the conceptual systemic model of patient safety, which expresses the organizational perspective of understanding accidents in medical-hospital care $^{(13)}$.

In such an approach, system operators are the inheritors of their defects rather than causing an accident. Therefore, in order to understand the errors, one must situate them in relation to the context in which people are working in order to search for the systemic factors that influence the professionals, instead of an isolated person-centered approach ${ }^{(13)}$.

When opting for this approach in this study, it is sought to demonstrate that the failures of those who operate the system, being those who exercise direct care actions of the patient and who therefore commit active failures, occur in specific contexts, often provided by latent conditions. These are linked to the decisions of those responsible for the projection of the system, its norms, routines and processes, which at one point may combine with factors of the individual, task, team, patient and threaten the security of the system ${ }^{(13)}$.

This is based on the assumption that the way the collaborative model in which the ICU nurse works in managing continuous HD may be one of these latent conditions that has repercussions on patient safety. The objective of this study was to describe the ICU nurse's role in managing continuous hemodialysis within the scope of the collaborative model, analyzing its relationship with patient safety.

\section{METHOD}

\section{Study DESIGN}

This is an exploratory-descriptive field study with a qualitative approach. The model proposed by James 
Reason, which is focused on the conditions that propitiate error and that integrates the theory of the human error, is the conceptual base of analysis ${ }^{(13)}$.

\section{SCENARIO}

The study scenario is a medium-sized institution in the municipality of Rio de Janeiro, a reference in specialized care. The locus was the ICU, which holds 26 beds intended for severe patients. There were 76 continuous HD sessions in the month of August 2016 (the investigation period), an average of 2.45 sessions per day, justifying the choice of this scenario.

In the research scenario, the collaborative model is composed of two dialysis nurses responsible for managing continuous HD: one has no specialization in nephrology, but has practical and theoretical experience regarding care for AKI patients; the other is accredited to work in the field of nephrology, including in HD management. These nurses are from the ICU and perform other patient care activities. The model also includes nephrologist physicians, intensive care sector shift workers/physicians, and/ or physician assistants.

The medical team elaborates the medical prescription in which there is an indication for continuous HD and the parameters for its accomplishment. This prescription is directed to the team of nurses on duty in the sector, responsible for the installation, maintenance and followup of this treatment. Dialysis nurses who manage continuous HD are activated on demand to clarify questions and problem-solving.

\section{Data collection}

The study participants were nurses in the adult ICU sector of the abovementioned hospital. The population was composed of a total of 49 nurses divided into day and night shifts, with a 12-hour work schedule and 60 hours rest, plus four workload completions, with an average of eight to nine nurses by work shifts, subdivided into the three ICU subunits.

The following inclusion criteria were established: being a nurse in the ICU; active in the industry during the data production period; to act directly in the care of critical patients submitted to continuous HD; to have another 3 months working in the unit during the period in which a newly hired professional receives training, not responding directly to patient care. Nurses working in the ICU but who were responsible for continuous HD management in the sector were excluded.

Participants were selected from the nurses who worked in the three subunits of the general ICU and both shifts. In order to do so there was an exploratory phase to get familiar with the scenario, to approach the participants and to invite them to participate in the study. This immersion in the field sought naturalization of the researcher with the participants and their theoretical preparation, in exercising the approach and withdrawal of the research phenomenon, considering their previous experience in the unit with continuous hemodialysis management in order to avoid bias in the analysis/interpretation.

Participants who accepted signed the Free and Informed Consent Form and received alphanumeric identification to guarantee their confidentiality, in which the code $\mathrm{C}=$ Interviewee, followed by their sequential order number.

Data production was subsequently started through interviews. A semi-structured script was designed for the interview based on a survey of the knowledge production on continuous $\mathrm{HD}^{(11-12)}$. It was composed of two parts: the first was aimed at collecting professional data about training and experience; and the second toward exploring the research object, whose questions alluded to the action in handling continuous HD, the difficulties faced, the qualifications, and the security incidents. A pilot test was performed with two nurses who were not included in the final data sample, and did not result in changes to the instrument's preliminary version.

The interviews with the nurses were performed in a reserved room in the same sector according to availability on the on call days, with a digital MP4 device and an average duration of 30 minutes. The criterion of theoretical saturation was used for concluding the interviews, meaning that when there was data repetition and no addition of new elements, and those obtained were enough to meet the objective in relation to the research phenomenon ${ }^{(14)}$.

This saturation was verified during the analysis phase based on applying the thematic content analysis technique $^{(15)}$. A floating reading of the material was initially performed, observing the messages contained therein. Then, the indicators were surveyed with the marking in each interview of the thematic registry units (RU). The sense in which these themes were mentioned was subsequently verified, organizing them into units of meaning, arranged in a worksheet in which the RU number was analyzed in each interview.

Such systematics made it possible to detect that the themes started to repeat in the $18^{\text {th }}$ interview in relation to those previously identified. Five more interviews were then carried out and the data production was completed, since the theoretical density needed to answer the question was verified. Therefore, the number of interviewees was 23 .

\section{Data ANALYSIS AND PROCESSING}

The units of meaning were recorded on a second worksheet with the RU number and its percentage. After this initial separation of the signification units, the contents were mapped in relation to the dimension in which they were transmitted, taking into account the safety reference of the research ${ }^{(13)}$, which served as the basis for inferences about the manifested/latent content. Regrouping by analogy was subsequently performed, enabling establishment of the categories and the survey of the RU number in order to demonstrate their significance.

\section{ETHICAL ASPECTS}

The project was approved by the Research Ethics Committee of the investigated institution in the year 
2016, under opinion no. 1.540.723, in compliance with Resolution no. $466 / 12$ of the National Health Council which deals with research with human beings. Participants who accepted signed the Free and Informed Consent Form.

\section{RESULTS}

\section{THE ICU NURSE'S ACTIVITIES IN THE CONTINUOUS HD COLLABORATIVE MODEL}

The set of RUs that referred to the ICU nurse's performance in relation to critical patients undergoing continuous HD enabled a description of their activities in face of the need to manage this technology. These activities develop in phases in which the nurse is inserted within the scope of their performance with this patient, as evidenced in 33 RUs.

The first one is preparation, marked by knowing the history and clinical evolution of the patient, the indications for continuous HD, an evaluation of the venous access where the HD will be inserted, a request of the necessary materials for beginning the treatment, and the equipment preparation by filling the continuous hemodialysis circuit with saline. After this initial process which integrates knowledge about the patient, the implemented therapy and equipment handling, the installation phase then occurs which involves connecting the patient to the HD equipment, and is performed by the nurse.

According to the nephrological prescription which will include the indication for that patient, we ask for the material, assemble the HD and do the tests that she asks us to do, the priming that we are doing before connecting the patient, which is to fill the circuit with the saline, and then we connect the patient to the $H D$ catheter (C11 - up to 5 years since graduating; up to 5 years in the industry; not an ICU specialist).

First is to assemble the HD, and the patient must have indication for this, have the request, prescription and catheter to start this HD. According to monitoring this therapy to observe and identify the abnormalities that may arise, for example, the alarms, and to make future interventions, follow the laboratory to verify the needs for adjustments in the machine (C12 - up to 5 years since graduating; specialist in the ICU).

The nurse 12 identifies the co-occurrence of the preparation and installation phase with the follow-up phase, something that was repeated in $11 \mathrm{RU}$. Laboratory tests are performed every 4 hours during follow-up, and electrolyte replacement is performed based on interpreting these tests. The nurse is responsible for these checks and monitoring the changes, since they have autonomy to perform adequacies of the concentrations and the speed of these infusions, in addition to other patient care.

So we basically manage the information requested by her, exchanging the bags, replacing electrolytes, schedules, and also check with the patient's laboratory to have parameters for changes in schedules and replacements (C10 - more than 10 years in the industry; more than 10 years since graduating; not an ICU specialist).
Both preparation stages, installation and follow-up occur from two characteristics, present in $15 \mathrm{RU}$. The first one is the interface that the nurse establishes with the technology that is coupled to the patient. The interviewees 15 and 21 contribute to support this statement when they state in their excerpts that the equipment "speaks" and sends them information that guides the handling.

The machine is "self-teaching", it says everything so that we can solve it (C15 - up to 5 years in the industry, 5 to 10 years since graduating, specialist in the ICU).

The machine is also very self-teaching, it tells you what the problem is, and then you go to the root of it to try to solve it in the best way possible (C21 - from 5 to 10 years in the industry; from 5 to 10 years since graduating; not an ICU specialist).

The second characteristic of nurses' performance is autonomy for decision-making regarding the evolution of HD based on interpreting the information emitted by the equipment and the patient. Therefore, it is necessary that this professional has knowledge about this technology in order to support their search for solutions to problems.

For example, if it is low sodium we can get it, it can go up a little according to the prescription, if the prescription is 10 milliliters per dialysate bag, we can go up to 20 milliliters, and then we titrate these electrolytes according to the gasometry this patient is showing us, both electrolytes and calcium chloride as well as citrate (C11 - up to 5 years since graduating; up to 5 years in the sector, not an ICU specialist).

Faced with the need for professionals' knowledge, the emergence among more experienced nurses reflects on this performance model in which ICU nurses are inserted into caring for continuous HD patients. Thus, acquiring this knowledge changes the ICU nurse's condition, differentiating it from their other colleagues.

It has changed because, in reality, it is rare or almost never that you see an ICU nurse who does dialysis on her own with her own patient, so at the beginning it generated a lot of expectation as to where our knowledge came from, how we handled everything. This is because it is different, someone comes on the dialysis and you observe, but it is in your hands thereafter, when you have the machine, the patient, that you are the dialysis nurse (C1 - more than 10 years since graduating; more than 10 years in the sector; not an ICU specialist).

(...) I do not know if it is a benefit or it is bad for us to assume this responsibility in another method that consists of almost an extracorporeal circulation of the patient, so it is a very big responsibility, but I look at with great learning, it's a differential from another professional who does not have this knowledge of the HD method (C21 - from 05 to 10 years in the industry; from 05 to 10 years since graduating; not an ICU specialist).

\section{Organization OF THE ICU NURSE's WORK IN THE COLLABORATIVE MODEL}

The characteristics of the nurse's activities in the context of patient care using continuous HD lead the investigated nurses to refer to the way the work is organized, to 
establish links with their performance and to discuss the repercussions of this organization on their professional performance in the perspective of patient safety. In this sense, the theme of the Organization of work obtained 23 RUs.

This is because such an assignment of the ICU nurse to conduct part of the continuous HD treatment is in addition to other tasks that they already develop in the field of intensive care. Thus, the nurse assumes a function that is the responsibility of the HD sector in other work places, thus constituting another work demand, a sub-item with 12 RUs.

In fact, it is an over-attribution that we have, we end up assuming another responsibility, we know that hemodialysis is a therapy that is usually handled by a specialist who accompanies this treatment (C1O-more than 10 years in the industry; more than 10 years since graduating; not an ICU specialist).

So, my job assignment has increased, because in the ICU where I work there is more responsibility, and so we often question: "Why do the nurses in this hospital do this and in the other hospital they do not?" It ended up that some nurses already left this service because of this, and went to work at another service also because of this (...) (C18 - up to 5 years in the industry; up to 5 years since graduating; not an ICU specialist).

Such demand causes an accumulation of nurse functions, as well as responding to the direct care of other patients who are under intensive care in the ICU and who also use life support technologies, and need to perform a set of care activities with the patient in continuous HD process, which takes up much of their time and attention. Thus, there is questioning of the work organization in relation to the number of patients per nurse, especially those who are inexperienced.

There is more exclusive dedication with these patients, because they require more care. It is a therapy that takes a lot of our time because you have to be evaluating the exams every 4 hours, the alarm on the machine goes off, the bag finishes, the nurses acting with this patient have to be more exclusive because when you are alone with this patient you feel the difference, you see that these patients need the nurse's attention (...) (C6 - from 05 to 10 years since graduating; up to 5 years in the sector, not an ICU specialist).

This accumulation of functions therefore causes work overload and can have repercussions on the health of the professional, and consequently on their performance, as indicated by seven RUs and illustrated by excerpts from nurses 7 and 9:

It ends up overwhelming us, in fact, because this work needs more attention, the problem is the increase in the workload during the shift. The overload undoubtedly has much more impact on the nurse's performance, making them work much more, making work worse (C9 - more than 10 years since graduating; more than 10 years in the industry; specialist in the ICU).

It ends up being a very big responsibility, it takes a lot of attention in manipulating, besides the prism, there are the drugs, the patient who is never alone with the prism only, I mean some- times they are as they improve, but in the first times it's never just him. There are always so many things, and the nurse has to give so much attention, so it becomes very stressful (C7 - up to 5 years since graduating; up to 5 years in the sector; not an ICU specialist).

Thus, the mode of work organization in continuous HD should be a factor for attention to patient safety, considering that the overload generates incident risks, as identified in $26 \mathrm{RUs}$, as those present in the reports below:

Sometimes the shift is so hectic that we cannot measure the gasometry at the correct time every 4 hours because you have two more patients, so you when see the gasometry 1 or 2 hours have already passed since the result and the patient's potassium was too low or too high. These are things that can harm their health and that you should pay more attention to, and not because of the overload, because you are with them and two other patients (C6 -from 5 to 10 years since graduating; up to 5 years in the industry; not an ICU specialist).

These incidents are the result of difficulties in meeting the patient demands in HD, exemplified by the machine alarms going off, reflection of the overload and fragilities related to the nurse's knowledge within the framework of the collaborative model:

The machine's alarm goes off and my colleague is very involved with the patient, not realizing what is happening, silencing the machine until she could no longer stand the alarm and lost the continuous hemodialysis kit (C18 - up to 5 years in the industry; up to 5 years since graduating; not an ICU specialist).

As it happened twice (difficulty with alarm) and we did not have the possibility to return the blood and we had to withdraw the therapy and reassemble the machine (C8 - from 5 to 10 years since graduating; up to 5 years in the industry; specialist in the ICU).

\section{DISCUSSION}

The results in category 1 deal with the ICU nurse of the investigated institution being inserted into caring for continuous HD patients, evidencing its importance in this context, since they assume care and administrative functions that demand knowledge about this care process. This need is relevant to be considered considering the activities that are performed in continuous HD, an aspect that appears in the results when they approach their participation in the follow-up phase of continuous HD with autonomy and security.

Some researchers have been concerned with this analysis of the qualification present in the empirical data ${ }^{(8,16-17)}$. An example is a production survey to identify citations about nursing management and care with continuous $\mathrm{HD}$, and information with machine manufacturers in the UK. From this the authors indicate principles to guide nursing practice to encounter what is conveyed in other productions ${ }^{(8,16)}$.

The first principle focuses on the patient's careful and constant evaluation, which involves: evaluating indications 
for continuous HD; having an understanding of the different types of $\mathrm{HD}$ available in order to recommend the choice of what best corresponds to the individual; understanding factors that affect blood flow and how to minimize complications ${ }^{(8,16)}$.

The second principle is to have vascular access with good blood flow. The catheter should be located in a central vein, well attached to the patient's skin to avoid accidental removal, have a double lumen and a length of $15-24 \mathrm{~cm}$. It is required that pump speed is adequate for the catheter puncture site to avoid unnecessary suction in the vessel wall. If the blood flow is still insufficient, consider changing the catheter. Washing the two lumens of the catheter with $0.9 \%$ sodium chloride is recommended when therapy is terminated, preventing thrombus formation ${ }^{(8,16)}$.

Preventing complications such as gas embolism is the third principle, to remove air from the circuit before connecting the equipment to the patient, which is performed with $0.9 \%$ sodium chloride, with or without heparin, according to the patient's condition ${ }^{(8,16)}$.

As the therapy removes fluids and electrolytes in an unselected way, it is necessary to verify the need to replace the electrolytes in the ultrafiltration replacement fluid at regular intervals (every 4-6 hours), and to analyze arterial blood gases for $\mathrm{pH}$ balance and increased lactate. Fluid balance management is also important so that hypovolemia does not occur, with drops in blood pressure, or hypervolemia with fluid overload, and continuous evaluation of vital signs ${ }^{(8,16)}$.

The patient's temperature should be monitored at least four times during $\mathrm{HD}$, and the replacement and/or dialysate fluids should be warmed prior to entering the circuit or the blood access lines. Exclusive intravenous access to continuous HD is used to minimize the risk of bloodstream infection; in the dressings, a transparent, semi-permeable cover should be applied every 7 days; any handling is aseptic ${ }^{(8,16)}$.

Providing coagulation of the filter is a useful aspect for nursing. Such a prediction is desirable to return blood from the circuit to the patient prior to coagulation and complete obstruction of the circuit. If the continuous HD parameters indicate circuit failure, treatment is stopped at a time when the blood can be returned to the patient ${ }^{(16)}$.

These ICU nurse activities are developed in a collaborative model in this study, in which the dialysis nurses responsible for continuous HD management do not perform these activities exclusively, as they also assume other care activities related to ICU patients. An analysis of the literature has indicated a current discussion on this subject, as it is observed in publications ${ }^{(8-9,17-18)}$.

In an Italian hospital, the problem faced by nursing administrators is that no general rule has been recommended for continuous HD in the ICU. Thus, the objective was to carry out a national survey on nursing practices during continuous renal replacement therapies. A total of 119 questionnaires were analyzed from 44 different hospitals and from 35 Italian cities. Overall, 23\% of respondents answered that "the dialysis team" was responsible for continuous renal replacement therapy in the ICU, while $39 \%$ responded that "critical care nurses" performed this task, and in 38\% "shared organization" was effective in the care ${ }^{(9)}$.
Other authors defend the collaborative model ${ }^{(8,18)}$. In this case, they affirm that there are challenges for ICU nurses to achieve and sustain proficiency in handling continuous HD. One of the reasons is that such an activity represents only part of its practice, which gives less motivation to qualification and research initiatives. Therefore, the nephrologist nurse is responsible for demonstrating the value of their practice, providing support for ICU nurses to sustain the best practices ${ }^{(18)}$.

When the dialysis unit is located near the ICU, the collaborative approach to nursing care can be helpful. The dialysis nurse would be responsible for preparing the machine, the circuit and initiating the treatment, while the ICU nurse would monitor continuity, managing the $\mathrm{HD}$ and alerting the dialysis nurse in case of a need for problem solving and circuit disconnection. The independent functioning of the ICU requires educational strategies to ensure the competence of professionals ${ }^{(8)}$.

These references depict controversies about who should start, deliver, and manage continuous methods. The collaborative model adopted at the institution in this study compromises the greater participation of dialysis nurses in the planning and implementation of follow-up activities of nursing care related to continuous $\mathrm{HD}$, as well as in advising the multidisciplinary team on decision making.

In turn, this makes it difficult to consolidate the nursing organization model regarding continuous HD in the ICU, which is still not well established according to the data that nurses from the ICUs of other institutions do not generally handle $\mathrm{HD}$, which raises questions about the subjects, mainly about the ICU nurse's knowledge about conducting the $\mathrm{HD}$ and the implications that this responsibility brings.

As a consequence, non-consolidation of the organization model for providing care for continuous HD by ICU nurses make it difficult to develop protocols and guidelines which give direction to the practice of ICU nurses in conducting the continuous HD with safety, with repercussions on their training/qualification.

This concern with qualification appears in other investigations ${ }^{(5,9)}$, such as in one that examined nursing practices regarding continuous HD in Canadian ICUs. Of the 73 instruments answered by those in charge of nursing education, the greatest concern was with the staff's education and the maintenance of their competence for managing continuous $\mathrm{HD}$, since not all maintained consistent training programs ${ }^{(5)}$.

It was also observed that the activities in the collaborative model of the unit take place within a work dynamic in which each nurse attends to the care of an average of two patients. In the empirical data, such organization causes the $\mathrm{HD}$ to be configured as an additional allocation for the nurse and results in an increase in their work demand.

Questioning the accumulation of functions supports the argument that the nurse should be exclusively available to the care of this patient, as evidenced in the excerpts of the nurses 6 and 11. Since this exclusive distribution does not occur, the inexperienced ones feel overwhelmed, as shown in their discourse about the stress, which can be contrasted with evidence of repercussions on working conditions from the perspective of safety ${ }^{(19-21)}$. 
A systematic review on the influence of nursing workload on the occurrence of adverse events found that overload influenced the outcome of infection and pressure ulcers ${ }^{(19)}$. Another study that evaluated the incidence of adverse events and its association with the nursing workload, team size and severity profile of the patient detected the occurrence of 39 adverse events in 304 admitted patients over 4 months. Patients who suffered adverse events had higher scores on the nursing workload, and there was no association with team size ${ }^{(20)}$.

Finally, a study that measured the nursing workload in 190 patients of an ICU with AKI verified that they had higher NAS (Nursing Activities Score) than patients without AKI, especially those classified in stages 2 and 3 who used advanced support such as $\mathrm{HD}$, thus requiring more nursing care ${ }^{(21)}$.

The Reason model is guided by the principle that 'to err is human'. So mistakes do not come from bad people, but from poorly designed systems. It is therefore necessary to know these defects in order to anticipate errors, which means to elaborate mechanisms and strategies to avoid error and mitigate adverse events. These mechanisms are the barriers to prevent errors from reaching the patient, similar to the layers of Swiss cheese $\mathrm{e}^{(13)}$.

Therefore, in this explanatory model it is proposed to weaken the latent errors of the system, creating complex defensive layers that consider the involved factors ${ }^{(13)}$. The research data point out that the configuration in organizing patient care in continuous HD is a latent error that makes it difficult to consolidate the ICU nurse's work.

This is due to the collaborative model not being effectively implemented, and therefore it jeopardizes the monitoring of its performance in detecting difficulties and implementing strategies to strengthen its competence, particularly for nurses with little practical experience. As a consequence there is an active failure, as reported by $\mathrm{C} 8$, who could not solve the alarm problem due to the difficulty of interpretation, causing the patient's blood loss.

In addition, because nurses in this model are responsible for caring for patients without $\mathrm{HD}$, there are difficulties to meet all the work demands, generating stress and overload which are reflected in practice and implicate patient safety.

\section{CONCLUSION}

The results indicate that the ICU nurse works in caring for patients undergoing continuous $\mathrm{HD}$ in performing preparation/planning and monitoring/follow-up activities, which occur from the interaction they establish with the technology and in applying specialized knowledge in the field of nephrology. This leads to clinical judgment and decision making with autonomy, so as to guarantee safety in their performance.

The adopted collaborative model is reflected in its qualification and availability in relation to the activities that nurses need to perform in managing the technology, affecting patient safety and weakening the role that ICU professionals perform in this therapy.

Greater participation by dialysis nurses is recommended as a safety barrier, being a reference to $\mathrm{HD}$ and based on elaborating a systematic follow-up program of nurses and to manage difficulties, with guidelines which help to support their performance. It is necessary to review the distribution of the patients per nurse due to the difficulties of inexperienced nurses in managing the demands and the complexity of continuous HD.

There are few national experiences of ICU nurses in continuous $\mathrm{HD}$, which was a limitation for data comparison and significance.

\section{RESUMO}

Objetivo: Descrever a atuação do enfermeiro da Unidade de Terapia Intensiva no manejo da hemodiálise contínua no âmbito do modelo colaborativo, analisando-a quanto aos nexos com a segurança do paciente. Método: Pesquisa exploratória-descritiva, qualitativa, baseada no modelo de segurança de Reason, realizada na Unidade de Terapia Intensiva de hospital especializado, com enfermeiros atuantes no manejo direto da hemodiálise contínua, os quais foram entrevistados com o uso de um roteiro cujos conteúdos passaram por análise temática. Resultados: Participaram 23 enfermeiros. A atuação do enfermeiro da terapia intensiva na hemodiálise contínua envolve executar atividades de preparo/planejamento e de monitorização/acompanhamento, a partir da interação com a tecnologia e da aplicação de conhecimentos especializados. O modelo colaborativo adotado traz reflexos na sua qualificação e disponibilidade frente às atividades que precisa executar, repercutindo na segurança do paciente. Conclusão: Há fragilidades na participação dos enfermeiros da terapia intensiva neste modelo de hemodiálise contínua que requerem a elaboração de barreiras defensivas para a segurança do sistema.

\section{DESCRITORES}

Enfermagem de Cuidados Críticos; Diálise Renal; Tecnologia Biomédica; Segurança do Paciente.

\section{RESUMEN}

Objetivo: Describir la actuación del enfermero de la Unidad de Cuidados Intensivos en el manejo de la hemodiálisis continua en el ámbito del modelo colaborativo, analizándola en cuanto a los nexos con la seguridad del paciente. Método: Investigación exploratoria descriptiva, cualitativa, basada en el modelo de seguridad de Reason, llevada a cabo en la Unidad de Cuidados Intensivos de hospital especializado, con enfermeros actuantes en el manejo directo de la hemodiálisis continua, quienes fueron entrevistados mediante un guión cuyos contenidos pasaron por análisis temático. Resultados: Participaron 23 enfermeros. La actuación del enfermero de cuidados intensivos en la hemodiálisis continua involucra llevar a cabo actividades de preparación/planificación y de monitoreo/seguimiento, desde la interacción con la tecnología y la aplicación de conocimientos especializados. El modelo colaborativo adoptado trae reflejos en su calificación y disponibilidad frente a las actividades que necesita llevar a cabo, repercutiendo en la seguridad del paciente. Conclusión: Hay fragilidades en la participación de los enfermeros de los cuidados intensivos en este modelo de hemodiálisis continua que requieren la creación de barreras defensivas para la seguridad del sistema.

\section{DESCRIPTORES}

Enfermería de Cuidados Críticos; Diálisis Renal; Tecnología Biomédica; Seguridad del Paciente. 


\section{REFERENCES}

1. Alenezi F, Alhazzani W, Ma J, Alanazi S, Salib M, Attia M, et al. Continuous venovenous hemofiltration versus continuous venovenous hemodiafiltration in critically ill patients: a retrospective cohort study from a Canadian tertiary centre. Can Respir J [Internet]. 2014 [cited 2016 May 31];21(3):176-80. Available from: https://www.ncbi.nlm.nih.gov/pmc/articles/PMC4128463/

2. Levi TM, Souza SP, Magalhães JG, Carvalho MS, Cunha AL, Dantas JG, et al. Comparison of the RIFLE, AKIN and KDIGO criteria to predict mortality in critically ill patients. Rev Bras Ter Intensiva [Internet]. 2013 [cited 2016 May 31];25(4):290-6. Available from: http://www. scielo.br/pdf/rbti/v25n4/en_0103-507x-rbti-25-04-0290.pdf

3. Gallagher M, Cass A, Bellomo R, Finfer S, Gattas D, Lee J, et al. Long-term survival and dialysis dependency following acute kidney injury in intensive care: extended follow-up of a randomized controlled trial. PLoS Med [Internet]. 2014 [cited 2016 May 31]; 11 (2): e1001601. Available from: https://www.ncbi.nlm.nih.gov/pmc/articles/PMC3921111/

4. Ponce D, Abrão JMG, Albino BB, Balbi AL. Extended daily dialysis in acute kidney injury patients: metabolic and fluid control and risk factors for death. PLoS One [Internet]. 2013 [cited 2016 May 31];8(12):e81697. Available from: https://www.ncbi.nlm.nih.gov/pmc/ articles/PMC3859511/

5. Bourbonnais FF, Slivar S, Tucker SM. Continuous Renal Replacement Therapy (CRRT) practices in Canadian hospitals: where are we now? Can J Crit Care Nurs. 2016;27(1):17-22.

6. Allegretti AS, Hundemer G, Chorghade R, Cosgrove K, Bajwa E, Bhan I. Perspectives of continuous renal replacement therapy in the intensive care unit: a paired survey study of patient, physician, and nurse views. BMC Nephrol [Internet]. 2015 [cited 2016 May 31];16:105. Available from: https://www.ncbi.nlm.nih.gov/pmc/articles/PMC4501124/

7. Cabrera AR, Adame JLN, Almaráz JEL. Terapias continuas de reemplazo renal en pacientes críticos con lesión renal aguda. An Med Asoc Med Hosp ABC [Internet]. 2015 [citado 2018 Mar. 12];60(2):110-7. Disponible en: http://www.medigraphic.com/pdfs/abc/bc-2015/bc152f. pdf

8. Baldwin I, Fealy N. Clinical nursing for the application of continuous renal replacement therapy in the intensive care unit. Semin Dial. 2009;22(2):189-93. DOI: 10.1111/j.1525-139X

9. Ricci Z, Benelli S, Barbarigo F, Cocozza G, Pettinelli N, Di Luca E, et al. Nursing procedures during continuous renal replacement therapies: a national survey. Heart Lung Vessel [Internet]. 2015 [cited 2016 May 31];7(3):224-30. Available from: https://www.ncbi.nlm.nih.gov/pmc/ articles/PMC4593015/

10. D'Ávila M. La enfermera de UCl: pieza clave para el éxito de las técnicas depurativas continuas. Enferm Intensiva [Internet]. 2012 [citado 2016 Mar. 12];23(1):1-3. Disponible en: https://www.sciencedirect.com/science/article/pii/S1130239911000903

11. Golestaneh L, Richter B, Amato-Hayes M. Logistics of renal replacement therapy: relevant issues for critical care nurses. Am J Crit Care. 2012;21(2):126-30.

12. Rewa O, Villeneuve PM, Eurich DT, Stelfox HT, Gibney RT, Hartling L, et al. Quality indicators in continuous renal replacement therapy (CRRT) care in critically ill patients: protocol for a systematic review. Syst Rev [Internet]. 2015 [cited 2016 May 31];4:102. Available from: https://www.ncbi.nlm.nih.gov/pmc/articles/PMC4520065/

13. Reason J. Human errors: models and management. BMJ. 2000;320(7237):768-70.

14. Minayo MCS. Amostragem e saturação em pesquisa qualitativa: consensos e controvérsias. Rev Pesq Qual [Internet]. 2017 [citado 2018 jan. 31];5(7):1-12. Disponível em: http://rpq.revista.sepq.org.br/index.php/rpq/article/view/82/59

15. Vaismoradi $\mathrm{M}$, Turunen $\mathrm{H}$, Bondas T. Content analysis and thematic analysis: implications for conducting a qualitative descriptive study. Nurs Health Sci. 2013;15(3):398-405. DOI: 10.1111/nhs.12048

16. Richardson A, Whatmore J. Nursing essential principles: continuous renal replacement therapy. Nurs Crit Care. 2015;20(1):8-15. DOI: $10.1111 /$ nicc. 12120

17. Cabrera LS, Alonso JM, Sánchez-Palacios M. Enfermería de cuidados intensivos y terapias continuas de reemplazo renal. Enferm Clin. 2009;19(2):95-7.

18. Ellis K. Who should provide continuous renal replacement therapies? Nephrology nurses are better prepared to provide CRRT. Nephrol Nurs J. 2007;34(2):228-9

19. Oliveira AC, Garcia PC, Nogueira LS. Nursing workload and occurrence of adverse events in intensive care: a systematic review. Rev Esc Enferm USP [Internet]. 2016 [cited 2018 Jan 31];50(4):679-89. Available from: http://www.scielo.br/scielo.php?script=sci_arttext\&pi $d=S 0080-62342016000400683$

20. Ortega DB, D'Innocenzo M, Silva LM, Bohomol E. Analysis of adverse events in patients admitted to an intensive care unit. Acta Paul Enferm [Internet]. 2017 [cited 2018 Jan 31];30(2):168-73. Available from: http://www.scielo.br/pdf/ape/v30n2/en_1982-0194-ape-30-02-0168.pdf

21. Coelho FUA, Watanabe M, Fonseca CD, Padilha KG, Vattimo MFF. Nursing activities score and acute kidney injury. Rev Bras Enferm [Internet]. 2017 [cited 2018 Jan 31];70(3): 499-505. Available from: http://www.scielo.br/pdf/reben/v70n3/0034-7167-reben-70-03-0475.pdf 